\title{
DESAJUSTES MACROECONÔMICOS E INFLEXÃO NA CONDUÇÃO DA POLÍTICA FISCAL BRASILEIRA
}

\author{
$\underline{\text { Jamile Almeida Silva }}{ }^{1}$ e Cleiton Silva de Jesus ${ }^{2}$ \\ 1. Bolsista PROBIC/UEFS, graduanda em Ciências Econômicas, Universidade Estadual de Feira de Santana, e-mail: \\ milealmeida92@gmail.com
}

2. Orientador, Departamento de Ciências Sociais Aplicadas, Universidade Estadual de Feira de Santana, e-mail: cleiton.uefs@gmail.com

PALAVRAS-CHAVE: macroeconomia; ajuste fiscal; economia brasileira.

\section{INTRODUÇÃO}

A sincronização dos instrumentos da Política Fiscal determina os rumos não só econômicos, mas também sociais de um país. A utilização da mesma influencia na qualidade de vida da população; com finanças públicas em ordem, o desenvolvimento econômico pode ocorrer sem entraves e os efeitos positivos são também sentidos pela sociedade.

Após o Regime de Metas Fiscais, estabelecido em 1999, a política fiscal passou a apoiar-se na defesa do equilíbrio orçamentário através de metas registradas formalmente. A Lei de Responsabilidade Fiscal (LRF), implantada em 2000, veio contribuir com este Regime, dando às finanças públicas novas atribuições, que visam a estabilidade físcal como forma de manter a dívida pública sob controle. No período que se seguiu após a implementação de tais recursos, o Brasil apresentou altos superávits primários, culminando no declínio das dívidas líquida e bruta.

No entanto, a partir do ano de 2014 o país apresentou resultados primários aquém dos esperados e estabelecidos pelas autoridades, fazendo com que tanto a dívida líquida quanto a bruta tomassem o rumo oposto dos últimos anos, ou seja, apresentassem crescimento. Como resposta, em 2015 foi iniciado um ajuste fiscal, visando a busca pelo equilíbrio financeiro e a recuperação da credibilidade brasileira. A forma como tal ajuste vem e deve ser feito tem sido discutida por economistas como Almeida el al (2015a), Gobetti (2015), Lisboa (2016), Salto e Marconi (2016), Afonso (2016) e mais tantas autoridades quando o assunto é finanças públicas. Apesar de haver discordâncias acerca de como deve ser feito o ajuste fiscal e de quais medidas devem ser tomadas, todos esses economistas observam problemas estruturais que acabam impactando negativamente a condução do mesmo. A exemplo disso, é possível ressaltar a dificuldade de se fazer um ajuste fiscal apenas baseado no lado da receita, considerando a carga tributária bruta como já elevada para o nível de desenvolvimento em que o Brasil se encontra, bem como a dificuldade de cortar alguns gastos.

Os fatores políticos também não contribuem para a tomada de medidas necessárias ao ajuste. A falta de sincronia entre o governo Dilma e a Câmara de deputados fez com que muitas medidas propostas pela equipe econômica da então presidente fossem rejeitadas, tornando ajuste fiscal um processo mais difícil que o esperado. Mais agravante, a abertura do processo de impeachment contra Dilma Rousseff, que culminou na entrada de Michel Temer 
como presidente interino, suscitou grandes repercussões na condução do ajuste fiscal. Mais de três meses após assumir a presidência, Temer ainda não mostrou medidas claras e isso alimenta o negativismos de alguns críticos ao seu governo e de economistas em geral.

\section{METODOLOGIA}

O trabalho observou a condução da política fiscal no período 1999-2016 a partir da elaboração de gráficos e tabelas, que analisaram dados estatísticos de fontes oficiais, como Tesouro Nacional, Banco Central do Brasil e Ipeadata.

\section{RESULTADOS}

A pesquisa desenvolvida por meio deste trabalho observou o desgaste da credibilidade brasileira a partir do segundo governo Lula. Foi percebido um afrouxamento na perseguição das metas de superávit primário, culminando em resultados aquém dos esperados a partir de 2014. Decorrente disso, houve um aumento das dívidas interna e externa. Também foi observado o aumento da inflação e da taxa de desemprego, além de uma queda no PIB.

A volta ao crescimento econômico deve contar com o alcance de bons resultados primários. Para que se retorne a trajetória de sucessivos superávits primários, observados nos anos iniciais da implantação do Regime de metas de inflação, o Brasil deverá colocar em prática medidas tanto do curto quanto de longo prazo. Dentre elas, o aumento de tributos e algumas reformas estruturais devem ocorrer.

\section{CONSIDERAÇÕES FINAIS}

O ajuste fiscal iniciado em 2015 conta com um quadro econômico bastante adverso: a atividade econômica continua em queda, o mercado de trabalho não dá sinais de melhoras, a inflação resiste acima do centro da meta e a dívida bruta deve chegar ao patamar de $90 \%$ até 2019. Do lado positivo é possível observar uma melhora nas contas externas, tanto por causa do baixo crescimento quanto por causa da desvalorização cambial, e o nível de confiança do consumidor voltou a crescer. Junto a isso, o PIB apresentou uma sutil melhora no segundo trimestre do ano presente, mostrando variação de 3,84\% em relação ao PIB do primeiro trimestre.

As medidas de ajuste fiscal tomadas até então ainda não surtiram efeito visível na economia. Isso é explicado pela impossibilidade de cortar alguns gastos no curto prazo e por fatores políticos, já que os governantes hesitam em tomar medidas que afetem a sociedade e as suas popularidades. Além do mais, a carga tributária brasileira já é considerada alta para o nível de desenvolvimento econômico em que o Brasil se encontra, e isso significa dizer que fazer um ajuste fiscal baseado apenas na elevação de tributos traria maiores danos à economia e ao bolso da população. 
O fato de Michel Temer se consolidar como presidente da república pode contribuir para que novas medidas sejam colocadas em prática. Em sua primeira reunião ministerial após se efetivar no cargo, Temer declarou que agora terá o espaço de tempo necessário para fazer o que vem prometendo e que a geração de emprego será prioridade em seu governo ${ }^{1}$.

A forma como Temer dará continuidade ao ajuste fiscal iniciado em 2015 gera especulações. Se tomadas medidas que persigam o aumento da receita e, consequentemente, a elevação da carga tributária, sobre qual parcela da população deverá recair o ônus? E quais os setores da economia que poderão ser mais afetados? Do lado das despesas, quais gastos serão efetivamente cortados no curto prazo? E quanto às reformas previstas, como elas impactarão a população?

Dessa forma, alguns cenários podem ser pensados. Há, por exemplo, a possibilidade de o governo continuar protelando o ajuste: manter a taxa de crescimento do gasto público e o nível da carga tributária. Nesse caso, haveria o aumento do déficit primário, que implicaria em dívida pública crescente, inflação acima da meta, juros altos, baixo crescimento e economia com baixa capacidade de geração de emprego. Um cenário mais otimista poderia contar com a criação de mecanismos que visem a melhora da administração dos gastos públicos e com a adoção de outras medidas de cunho estrutural, dentre as muitas analisadas na quarta seção deste trabalho. Tais mudanças podem contribuir para que a política fiscal retome sua credibilidade e sua condução se dê de forma mais eficiente à verificada nos últimos anos, buscando atingir resultados que não se limitem à atual conjuntura, mas que se estenda ao longo prazo.

\section{REFERENCIAS (principais referências)}

AFONSO, J. R. “As contas de Dilma podem ser reprovadas?”: entrevista. [16 jun. 2015]. Brasília: Estadão. Entrevista concedida a João Villaverde. Disponível em: < http://economia.estadao.com.br/blogs/joao-villaverde/as-contas-de-dilma/>. Acesso em: 16 jun. 2015.

ALMEIDA, Mansueto; LISBOA, Marcos de Barros; PESSOA, Samuel. O ajuste inevitável ou o país que ficou velho antes de se tornar desenvolvido. Julho de 2015.

APPY, B.; LISBOA, M. de B.; MENDES, M.; LAZZARINI, S. Os desafios para sair da crise. Estadão. 12 de setembro de 2015. Disponível em: $<$ http://economia.estadao.com.br/noticias/geral,osdesafiosparasairdacrise,1761199>. Acesso em: 03 de abril de 2016.

BACHA, Edmar. Para o governo caber em suas receitas. O Globo, 07 jun. 2016. Disponível em: <http://noblat.oglobo.globo.com/geral/noticia/2016/06/para-o-governo-caberem-suas-receitas.html>. Acesso em: 08 jun. 2016.

DE BOLLE, Monica. A cama de Oblomov. Estadão, 17 ago. 2016. Disponível em: $<$ http://economia.estadao.com.br/noticias/geral,a-cama-de-oblomov,10000069963>. Acesso em: 26 ago. 2016.

\footnotetext{
1 Ver mais informações acerca da posse definitiva de Temer em: $<$ http://noticias.uol.com.br/politica/ultimas-noticias/2016/08/31/michel-temer-assume-presidencia-darepublica.htm>.
} 
CURADO, M. Ajuste fiscal à brasileira. Marcelo Curado, 03 jun. 2016b. Disponível em: <https://marcelocurado.wordpress.com/2016/06/03/ajuste-fiscal-a-brasileira/>. Acesso em: 03 jun. 2016.

CURADO, Marcelo; NASCIMENTO, Gabrieli Muchalak. O governo Dilma: da euforia ao desencanto. Revista Paranaense de Desenvolvimento, Curitiba, v. 36, n. 128, p. 3348, jan./jun. 2015.

GOBETTI, Sérgio Wulff. ORAIR, Rodrigo Octávio. Flexibilização fiscal: novas evidências e desafios. Ipea. 2015.

HOLLAND, M. 'Governo levou gasto público ao colapso': entrevista. [5 de maio, 2016]. São Paulo: Estadão. Entrevista concedida a Francisco Carlos de Assis. Disponível em: $<$ http://economia.estadao.com.br/noticias/geral,governo-levou-gasto-publico-aocolapso,10000049174>. Acesso em: 04 jul. 2016.

LEITÃO, Miriam. Governo ambíguo. O Globo, São Paulo, 24 jul 2016. Disponível em: < http://blogs.oglobo.globo.com/miriam-leitao/post/governo-ambiguo.html $>$. Acesso em: 26 jul. 2016.

LISBOA, M. Roda Viva com Marcos Lisboa: entrevista. [28 de março, 2016]. Programa Roda Viva. Entrevista concedida a Augusto Nunes e bancada formada por Catherine Vieira, José Roberto Caetano, Naiana Oscar, Érica Fraga e Luís Lima. Disponível em: $<$ https://www.youtube.com/watch?v=MioU 7uQ0eE $>$. Acesso em 31/03/2016.

MENDES, Marcos. $O$ crescimento de longo prazo da economia brasileira tem sido satisfatório? 2013.

MINISTÉRIO DO PLANEJAMENTO. Estratégia de política econômica para recuperação do crescimento. Março de 2015.

OREIRO, José Luis. Evolução do regime de política econômica no Brasil (19992014): do "tripé macroeconômico" à "nova matriz macroeconômica". In: OREIRO, José Luis. Macroeconomia do desenvolvimentismo: uma perspectiva keynesiana. Rio de Janeiro: LTC, 2016, p. 181-2016.

PÊSSOA, Samuel. Dois caminhos. Folha de São Paulo, 14 out. 2014. Disponível em: $<\quad$ http://www1.folha.uol.com.br/colunas/samuelpessoa/2014/10/1534677-doiscaminhos.shtml>. Acesso em: 28 ago. 2016.

RIOS, Thiago Henrique; DE JESUS, Cleiton Silva. Consumer confidence and household spending: evidence from Brazil. 2016 (a publicar).

SALTO, Felipe; MARCONI, Nelson. O novo emplastro Brás Cubas. Agosto, 2015. Disponível em: <https://blogdosalto.wordpress.com/2015/08/30/o-novo-emplasto-bras-cubasfolha-ilustrissima-300815/>. Acesso em: 30 ago. 2015.

SCHWARTSMAN, A. Síndrome de Campinas. Folha de São Paulo, 11 mai. 2016. Disponível em:

http://www1.folha.uol.com.br/colunas/alexandreschwartsman/2016/05/1769946-sindrome-decampinas.shtml?cmpid\#>. Acesso em: 11 de mai. 2016.

VILLAVERDE, João. A escalada do abismo físcal. Estadão, 10 ago. 2016. Disponível em: $<$ http://economia.estadao.com.br/blogs/joao-villaverde/a-escalada-doabismo-fiscal/>. Acesso em: 10 ago. 2016. 